\title{
SOUTH AMERICAN COLLABORATION IN SCIENTIFIC PUBLICATIONS ON LEISHMANIASIS: BIBLIOMETRIC ANALYSIS IN SCOPUS (2000-2011)
}

Charles HUAMANí(1), Franco ROMANí(1), Gregorio GONZÁLEZ-ALCAIDE(2), Miluska O. MEJIA(3), José Manuel RAMOS(4), Manuel ESPINOZA(1) \& César CABEZAS(1)

\begin{abstract}
SUMMARY
Objectives: Evaluate the production and the research collaborative network on Leishmaniasis in South America. Methods: A bibliometric research was carried out using SCOPUS database. The analysis unit was original research articles published from 2000 to 2011, that dealt with leishmaniasis and that included at least one South American author. The following items were obtained for each article: journal name, language, year of publication, number of authors, institutions, countries, and others variables. Results: 3,174 articles were published, 2,272 of them were original articles. 1,160 different institutional signatures, 58 different countries and 398 scientific journals were identified. Brazil was the country with more articles (60.7\%) and Oswaldo Cruz Foundation (FIOCRUZ) had $18 \%$ of Brazilian production, which is the South American nucleus of the major scientific network in Leishmaniasis. Conclusions: South American scientific production on Leishmaniasis published in journals indexed in SCOPUS is focused on Brazilian research activity. It is necessary to strengthen the collaboration networks. The first step is to identify the institutions with higher production, in order to perform collaborative research according to the priorities of each country.
\end{abstract}

KEYWORDS: Leishmania; Neglected diseases; South America; Biomedical research; Community networks; Analysis; Bibliometric.

\section{INTRODUCTION}

Leishmaniasis is considered a "neglected tropical disease" by the World Health Organization ${ }^{19}$, with a worldwide distribution affecting mainly tropical and developing countries. It is characterized by a variety of clinical conditions that include the visceral and tegumentary forms, the latter of which has two: cutaneous and mucocutaneous ${ }^{8,17}$. These are the most frequent forms in Latin America, where 66,941 cases of cutaneous leishmaniasis were reported per year, between 2004 and 2008, mostly in Brazil, Colombia and Peru ${ }^{2,6}$.

Though leishmaniasis is a public health problem in many Latin American countries, the production of scientific literature on this disease is concentrated in Brazil, in collaboration with institutes in the United States, United Kingdom and France ${ }^{1,16}$. This is despite many South American countries having included leishmaniasis among their national research priorities, in order to ensure the best possible use of their resources to develop policies, standards, scientific knowledge, and health technology for its control, prevention and treatment $t^{4,15}$. Within this context, identifying the institutions that presently contribute to the development of leishmaniasis research is necessary, particularly within the South American sector.

The first step for increasing and improving scientific production from a broad range of Latin American countries is to identify the research groups with the highest levels of production and identify their collaborative networks.

The intention is to identify and characterize collaborative research networks and foster the exchange and transfer of technology and knowledge. This is particularly pressing in the wake of the formation of the Union of South American Nations (UNASUR; www.unasurg.org) and the UNASUR Network of National Institutes of Health (RINS), whose objectives are to strengthen the exchange of knowledge and develop cooperation programs. For these reasons, the aim of this study is to describe the characteristics of scientific collaborations, researching leishmaniasis in South American countries between 2000 and 2011, as shown by scientific publications, and to identify the primary collaborative networks at the regional level. Results will comprise an up-to-date reference of the institutions investigating leishmaniasis in the region.

\section{METHODOLOGY}

Design and study population: The bibliometric study that was conducted searched for and extracted publications in SCOPUS from 2000 to 2011 which dealt with leishmaniasis and included at least one South American author. The SCOPUS database was selected because it included all MEDLINE journals and contained the largest collection 


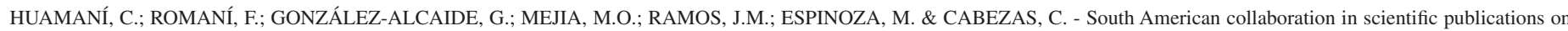
leishmaniasis: bibliometric analysis in SCOPUS (2000-2011). Rev. Inst. Med. Trop. Sao Paulo, 56(5): 381-90, 2014.

of Latin American journals ${ }^{5}$. Additionally, it registered the institutional affiliation of all authors, necessary for the analysis of collaborative networks. The database search was conducted in October, 2012.

Search strategy: Titles, abstracts and keywords were searched using the truncated word leishman*, in order to include the terms leishmania, leishmaniasis, and leishmaniosis. The search was limited to peer-reviewed, original research articles published within countries that make up the South American sector of the Latin American and Caribbean regions, according to the classification of the United Nations (twelve countries: Argentina, Bolivia, Brazil, Chile, Colombia, Ecuador, Guyana, Paraguay, Peru, Suriname, Uruguay, and Venezuela) between 2000 and 2011.

Manual revisions were carried out for each title and abstract, removing the revisions, reports/case series, short communications, letters to the editor, image galleries, and symposia. Articles that were not related to the topic of leishmaniasis (abstracts that mentioned the term leishman*) were also excluded. Two different authors performed the revision (FR and MM), and when doubts arose they were resolved by consensus, reviewing the article in extenso with a third author (CHS).

Variables: From each article, the following variables were obtained: journal name, language and year of publication. The years of publication were categorized into two sub-periods, 2000-2005 and 2006-2011. Methodological quality of the articles was not assessed. The journals' impact factors were obtained from Journal Citation Reports (JCR) 2011.

The number of authors, institutions and countries that participated was identified for each article. Since the analysis focused on the collaboration between institutions, their names were corrected manually when they were incomplete, translated incorrectly, or contained typographical errors. Following a methodology described previously ${ }^{13}$, this methodology was complemented with a search on the web of the profile of the authors or the institutions address. In this way, the following variables were obtained:

- Author's signature: Number of authors per article.

- Institutional signature: Institutional affiliation declared by the authors in the article - for which there may be more than one.

- Country's signature: Country that the authors declare in their institutional signatures.

When the institutional signature included any ministry of health, it was only considered if no additional hospital, institute or other institution with legal autonomy was indicated. From this, the interinstitutional (participation by two or more institutional signatures in one article) and international (participation by two or more signatory countries in one article) collaboration were evaluated. No collaborations between authors were evaluated, as these present more variants (appearing differently in their articles or changed institutional affiliations within the same period) that would have biased our analysis.

Data analysis: Frequency and percentage analyses were performed using SPSS v17.0 statistical software. The most productive institutions and countries, the number of collaborations between them (signatures that are related to each other by the number of joint publications), the number of publications per year, and the journal with the most publications were determined. To contrast the number of articles produced by South
American countries, the number of publications was compared with the estimated number of annual cases of visceral and cutaneous leishmania ${ }^{2}$ and scientific/technological development indicators ${ }^{18}$.

To illustrate the collaborative networks, the Pajek v.3.0.2 visual representation program was used, applying the Kamada-Kawai algorithm. This allows graphing the entire network, weighing the collaboration intensities, in addition to being understandable intuitively ${ }^{14}$. Furthermore, three bibliometric indicators were obtained. They allow assessing the relationship of the institutions with collaborative networks, which are:

- Degree of collaboration: this indicates the number of collaborators, which is a measurement reflecting the degree of interinstitutional connection.

- Intermediation: this assesses the extent that an institution was in the middle or allowed the interconnection between other network members; therefore, it measures the access and control of information flows.

- Proximity: this reflects the closeness of each institution with the remaining members comprising the network, assessing the interactive capacity of its peers.

\section{RESULTS}

In the SCOPUS database, 3,174 publications were retrieved for the entire study period. Following the manual review of the title and abstract of each publication, 2,272 $(71.6 \%)$ original articles entered into the analysis. The excluded items were $282(8.9 \%)$ review articles, $113(3.6 \%)$ case reports, $73(2.3 \%)$ letters to the editor, $12(0.4 \%)$ case series, nine $(0.3 \%)$ short communications, three $(0.1 \%)$ image galleries, three $(0.1 \%)$ symposia, one $(0.03 \%)$ conference abstract, and one $(0.03 \%)$ thesis. Furthermore, 405 (12.8\%) publications were excluded for addressing issues not related to leishmaniasis.

Scientific production per year: In absolute terms, the number of original articles increased, during the study period, from 87 original articles in 2000 to 293 in 2011 (Fig. 1). During the period from 2000 to 2005 , there were 749 articles $(33.0 \%)$ published, while from 2006 to 2011 , this number grew to $1,519(67.0 \%)$.

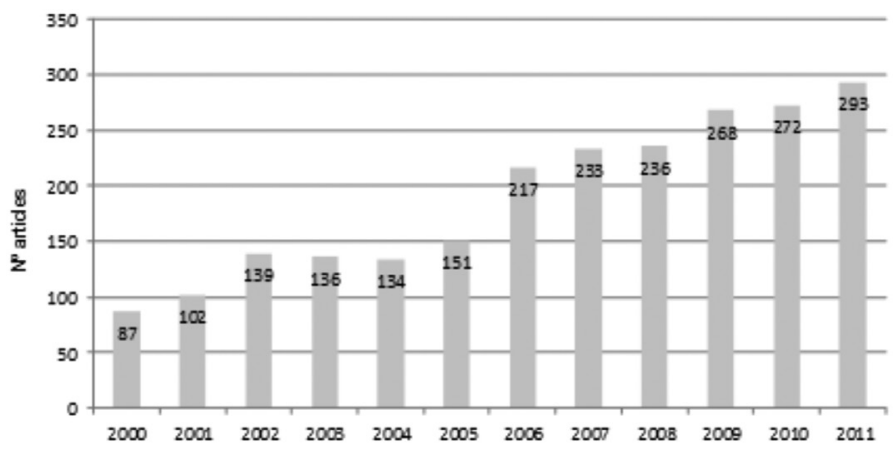

Fig. 1 - Number of original articles on leishmaniasis produced by South American countries, 2000-2011.

Publication language: English was the most common publication language $(87.6 \%)$, followed by Portuguese (8.9\%), Spanish $(3.2 \%)$, French $(0.2 \%)$, and German $(0.04 \%)$. From 2000 to 2005 , the 


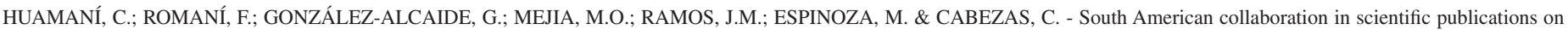
leishmaniasis: bibliometric analysis in SCOPUS (2000-2011). Rev. Inst. Med. Trop. Sao Paulo, 56(5): 381-90, 2014

predominant language used in original leishmaniasis articles was English (92.3\%), which decreased to $85.3 \%$ during the period from 2006 to 2011 . In contrast, Portuguese was used in $5.5 \%$ of the articles from 2000 to 2005, and then for 2006-2011, its use grew to 10.7\%. As for Spanish, $2.0 \%$ of the total articles from 2000 to 2005 appeared in said language, while for 2006-2011, the number grew to $3.8 \%$. In absolute terms, the number of articles in Portuguese increased from 41 (2000-2005) to 162 (2006-2011), while the number of articles in English increased from 691 (2000-2005) to 1296 (2006-2011).

Journals of publication: The total number of articles appeared in 398 scientific journals. Eight of them accounted for $32.3 \%$ of the articles on leishmaniasis. One-half of the South American scientific production was published in 21 journals, while the other half was scattered throughout 379 journals. The number of journals publishing only one article on leishmaniasis was 198. Forty-six journals contained $65.5 \%$ of the publications. The two journals publishing the most articles on leishmaniasis were Brazilian; Memórias do Instituto Oswaldo Cruz and Revista da Sociedade Brasileira de Medicina Tropical which together accounted for $11.2 \%$ of the articles throughout the entire study period. The journals with the highest impact factor were Clinical Infectious Diseases $(9,154)$, Journal of Immunology $(5,788)$, and the Journal of Antimicrobial Chemotherapy (5,068) (Table 1).

Number of authors and institutions: The median number of authors per article was six with an interquartile range from five to eight. The trend was five authors. There were 10 authors or fewer in $91.5 \%$ of the articles, $0.4 \%$ of them had only one, $54.2 \%$ listed from two to six authors, and $45.4 \%$ had seven or more. One article listed 101 authors. The median number of authors per article remained constant in all years.

Regarding the number of institutional affiliations per article, the median and trend was two. The interquartile range was from two to three, i.e., $50 \%$ of the articles had two or three affiliated institutions: $32.3 \%$ cited two different institutional affiliations and $22.8 \%$ cited three. Just under a quarter of the articles listed a single institution, while $20.7 \%$ listed four institutions or more. One article listed 24 collaborating institutions. The median number of institutions remained constant in all years.

Production per country: The identified institutions represented 58 different countries. Twenty countries accounted for $97.7 \%$ of the signatures. Brazil was the country with the most signatures $(60.7 \%)$, followed by the United States (7.1\%), Venezuela (4.9\%), and Colombia $(4.4 \%)$. Fifteen countries registered a single institutional signature. Five countries registered two institutional signatures, another five had three signatures and three of the countries registered four institutional signatures. Two countries had five institutions represented, three countries registered six institutions, three countries had ten, and two countries registered twelve signatures. Table 2 compares the production by South American countries with the annual number of leishmaniasis cases and other scientific/technological development indicators.

Production per institution: The 2,272 original articles had 1,160 different institutional signatures. Most institutions with higher quantities come from Brazil and include the Oswaldo Cruz Foundation (FIOCRUZ), with $11 \%$ of South American production and $18 \%$ of Brazilian production. It is followed by the University of São Paulo, the Federal University of Minas Gerais, the Federal University of Rio de Janeiro, and the Federal University of Bahia (Table 3). The top four institutions also have the highest degree of collaboration, working with more than 100 different institutions, in addition to the highest values of intermediation and proximity to other network members.

Among the institutions with fewer than 100 articles, but with high values for degree of collaboration, intermediation and proximity are the Cayetano Heredia University, the London School of Hygiene and Tropical Medicine, and the University of Antioquia. Table 4 shows the non-South American countries and their institutions with the highest quantities of signatures for original articles on leishmaniasis produced by South American countries.

Collaborative networks: One large collaborative network was identified (Fig. 2) along with five smaller ones (Fig. 3). The largest network is centered on Brazilian institutions, whose production center is FIOCRUZ. This institution collaborates intensely with the five most productive institutions and collaborates independently with several institutions primarily in Brazil, the USA, and the United Kingdom. The largest network has two extensions, the first of which derives from the collaboration between the Federal University of Rio de Janeiro with the Venezuelan Institute for Scientific Research, which then integrates other Venezuelan institutions into the network. The second extension begins at the Evandro Chagas Institute of Brazil, followed by the London School of Hygiene and Tropical Medicine of the United Kingdom, and concludes with the Cayetano Heredia University of Peru (UPCH), which then integrates European institutions that are primarily Belgian. Beyond the Venezuelan and Peruvian collaboration in these large networks, no collaboration with other South American institutions is evident.

The five smaller collaborative networks are constituted by i) four Japanese universities, the Catholic University of Santiago de Guayaquil, and the Ministry of Public Health of Ecuador; ii) exclusively Argentinean institutions; iii) Venezuelan institutions for Scientific Research with the University of Wurzburg (Germany); iv) Colombian institutions (Del Valle University and International Center of Training and medical research-CIDEIM) with Yale University; and v) two Colombian universities.

\section{DISCUSSION}

Overall, collaborations between South American institutions have been reported in other studies ${ }^{12,13}$ as being intense and including all countries in the region. However, in the case of collaborations for leishmaniasis research, (with the exception of the collaboration between Brazil and Venezuela, and to a lesser extent with Peru), South American countries collaborate less intensively. Leishmaniasis research has characteristics that differentiate it from other diseases. Individuals affected by the disease are usually rural, low-income, and there is low incidence in European countries and the United States, where the predominant clinical form is visceral leishmaniasis ${ }^{17}$. Because of these characteristics, leishmaniasis is not considered a research priority in these countries, which reduces the potential for collaborative research with South American countries. Furthermore, pharmaceutical industry investment is low, thus new drugs with fewer side effects and lower toxicity are not being developed. These characteristics, among others, have led leishmaniasis to be characterized as a "forgotten disease" (also known as "neglected tropical disease")" 


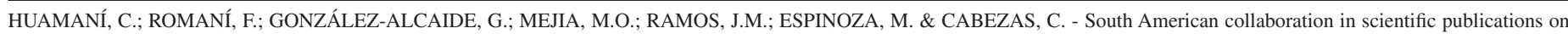
leishmaniasis: bibliometric analysis in SCOPUS (2000-2011). Rev. Inst. Med. Trop. Sao Paulo, 56(5): 381-90, 2014.

Table 1

Scientific journals containing two-thirds of the scientific articles published on leishmaniasis produced by South American countries, 2000-2011

\begin{tabular}{|c|c|c|c|c|c|}
\hline $\mathrm{N}^{\circ}$ & Journal & $\mathrm{n}$ & $\%$ & Country & Impact Factor $(2011)^{\mathrm{a}}$ \\
\hline 1 & Memorias do Instituto Oswaldo Cruz & 146 & 6.4 & Brazil & 2.147 \\
\hline 2 & Revista da Sociedade Brasileira de Medicina Tropical & 109 & 4.8 & Brazil & 0.681 \\
\hline 3 & American Journal of Tropical Medicine and Hygiene & 102 & 4.5 & USA & 2.592 \\
\hline 4 & Experimental Parasitology & 83 & 3.7 & USA & 2.122 \\
\hline 5 & Veterinary Parasitology & 78 & 3.4 & Netherlands & 2.579 \\
\hline 6 & Parasitology Research & 77 & 3.4 & Germany & 2.149 \\
\hline 7 & Acta Tropica & 73 & 3.2 & Netherlands & 2.722 \\
\hline 8 & Transactions of the Royal Society of Tropical Medicine and Hygiene & 65 & 2.9 & Netherlands & 2.022 \\
\hline 9 & Vaccine & 45 & 2.0 & Netherlands & 3.766 \\
\hline 10 & Molecular and Biochemical Parasitology & 44 & 1.9 & Netherlands & 2.551 \\
\hline 11 & Cadernos de Saude Publica & 37 & 1.6 & Brazil & 0.889 \\
\hline 12 & Antimicrobial Agents and Chemotherapy & 34 & 1.5 & USA & 4.841 \\
\hline 13 & Revista do Instituto de Medicina Tropical de Sao Paulo & 34 & 1.5 & Brazil & 1 \\
\hline 14 & Parasitology & 33 & 1.5 & UK & 2.961 \\
\hline 15 & Infection and Immunity & 29 & 1.3 & USA & 4.165 \\
\hline 16 & Journal of Medical Entomology & 28 & 1.2 & USA & 1.762 \\
\hline 17 & PLoS Neglected Tropical Diseases & 27 & 1.2 & USA & 4.716 \\
\hline 18 & Journal of Infectious Diseases & 26 & 1.1 & USA & 6.41 \\
\hline 19 & Parasite Immunology & 23 & 1.0 & UK & 2.601 \\
\hline 20 & Veterinary Immunology and Immunopathology & 22 & 1.0 & Netherlands & 2.076 \\
\hline 21 & International Journal for Parasitology & 20 & 0.9 & UK & 3.393 \\
\hline 22 & Brazilian Journal of Medical and Biological Research & 19 & 0.8 & Brazil & 1.129 \\
\hline 23 & Journal of Parasitology & 19 & 0.8 & USA & 1.405 \\
\hline 24 & Neotropical Entomology & 19 & 0.8 & Brazil & 0.603 \\
\hline 25 & Microbes and Infection & 18 & 0.8 & Italy & 3.101 \\
\hline 26 & Revista Brasileira de Parasitologia Veterinaria & 18 & 0.8 & Brazil & 0.712 \\
\hline 27 & PLoS ONE & 17 & 0.7 & USA & 4.716 \\
\hline 28 & Journal of Clinical Microbiology & 16 & 0.7 & USA & 4.153 \\
\hline 29 & Journal of Ethnopharmacology & 16 & 0.7 & Ireland & 3.014 \\
\hline 30 & Bioorganic and Medicinal Chemistry & 15 & 0.7 & UK & 2.921 \\
\hline 31 & European Journal of Medicinal Chemistry & 15 & 0.7 & Italia & 3.346 \\
\hline 32 & Annals of Tropical Medicine and Parasitology & 14 & 0.6 & UK & 1.429 \\
\hline 33 & Arquivo Brasileiro de Medicina Veterinaria e Zootecnia & 14 & 0.6 & Brazil & 0.291 \\
\hline 34 & Journal of Immunology & 13 & 0.6 & USA & 5.788 \\
\hline 35 & Parasitology International & 13 & 0.6 & Ireland & 2.132 \\
\hline 36 & Tropical Medicine and International Health & 13 & 0.6 & UK & 2.795 \\
\hline 37 & Anais Brasileiros de Dermatologia & 12 & 0.5 & Brazil & 0.554 \\
\hline 38 & Infection & 12 & 0.5 & Germany & 2.659 \\
\hline 39 & Journal of Venomous Animals and Toxins Including Tropical Diseases & 12 & 0.5 & Brazil & 0.429 \\
\hline 40 & Revista de Saude Publica & 12 & 0.5 & Brazil & 1.328 \\
\hline 41 & BMC Infectious Diseases & 11 & 0.5 & UK & 3.118 \\
\hline 42 & Clinical Infectious Diseases & 11 & 0.5 & USA & 9.154 \\
\hline
\end{tabular}




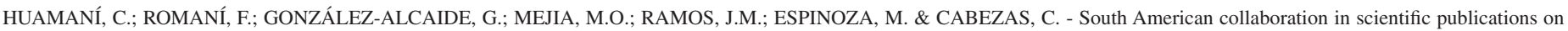
leishmaniasis: bibliometric analysis in SCOPUS (2000-2011). Rev. Inst. Med. Trop. Sao Paulo, 56(5): 381-90, 2014.

Table 1

Scientific journals containing two-thirds of the scientific articles published on leishmaniasis produced by South American countries, $2000-2011$ (cont.)

\begin{tabular}{llcccc}
\hline $\mathrm{N}^{\circ}$ & Journal & $\mathrm{n}$ & $\%$ & Country & Impact Factor $(2011)^{\mathrm{a}}$ \\
\hline $\mathbf{4 3}$ & Journal of Antimicrobial Chemotherapy & 11 & 0.5 & UK & 5.068 \\
$\mathbf{4 4}$ & Biomedica & 10 & 0.4 & Colombia & 0.545 \\
$\mathbf{4 5}$ & Brazilian Journal of Pharmacognosy & 10 & 0.4 & Brazil & 0.261 \\
$\mathbf{4 6}$ & Phytomedicine & 10 & 0.4 & Germany & 3.268 \\
\hline
\end{tabular}

ampact Factor by JCR 2011.

Table 2

Comparison of the production by South American countries with the number of annual cases of leishmaniasis and other indicators of scientific/technological development

\begin{tabular}{|c|c|c|c|c|c|c|}
\hline $\mathrm{N}^{\circ}$ & Country & Papers published & CL cases/year ${ }^{\mathrm{a}}$ & VL cases/year ${ }^{\mathrm{a}}$ & $\mathrm{RDE}^{\mathrm{b}}$ (million dollars) & $\mathrm{RDE} / \mathrm{GDP} \%^{\mathrm{b}}$ \\
\hline 1 & Brazil & 3552 & 26008 & 3481 & $20,237.6$ & 1.07 \\
\hline 2 & Venezuela & 285 & 2480 & 40 & ND & ND \\
\hline 3 & Colombia & 256 & 17420 & 60 & 600.6 & 0.16 \\
\hline 4 & Argentina & 218 & 261 & 8 & $2,658.7$ & 0.51 \\
\hline 5 & Peru & 124 & 6405 & - & 238.1 & 0.15 \\
\hline 6 & Bolivia & 44 & 2647 & - & ND & 0.26 \\
\hline 7 & Ecuador & 35 & 1724 & - & 145.9 & 0.15 \\
\hline 8 & Paraguay & 19 & 431 & 48 & 20.1 & 0.20 \\
\hline
\end{tabular}

CL. Cutaneous Leishmania, VL: Visceral Leishmania, RDE: Research and Development Expenditure, GDP: Gross domestic product. a Source: Alvar J, Velez ID, Bern C, et al. Leishmaniasis worldwide and global estimates of its incidence. PloS one. 2012;7(5):e35671(Alvar et al. 2012). ${ }^{\mathbf{b}}$ UNESCO (2010) UNESCO Science Report. The Current Status of Science around the World.

Table 3

Bibliometric indicators of the institutions with the largest number of signatures in original articles on leishmaniasis produced by South American countries in SCOPUS, 2000-2011

\begin{tabular}{|c|c|c|c|c|c|c|c|}
\hline Order & Institution & Country & Papers & $(\%)$ & Degree & $\begin{array}{c}\text { Interm. } \\
\text { x } 100 \\
\end{array}$ & $\begin{array}{c}\text { Proximity } \\
\text { x } 100 \\
\end{array}$ \\
\hline 1 & Oswaldo Cruz Foundation/Fiocruz & Brazil & 652 & $(11.1)$ & 315 & 33.1 & 53.7 \\
\hline 2 & Universidade de São Paulo & Brazil & 322 & $(5.5)$ & 222 & 18.1 & 48.3 \\
\hline 3 & Universidade Federal de Minas Gerais & Brazil & 266 & $(4.5)$ & 148 & 7.8 & 44.1 \\
\hline 4 & Universidade Federal do Rio de Janeiro & Brazil & 196 & $(3.4)$ & 122 & 7.5 & 44.7 \\
\hline 5 & Universidade Federal da Bahia & Brazil & 126 & $(2.2)$ & 98 & 2.9 & 42.0 \\
\hline 6 & Universidade Estadual Paulista & Brazil & 102 & $(1.7)$ & 64 & 3.4 & 40.6 \\
\hline 7 & Instituto Evandro Chagas & Brazil & 98 & $(1.7)$ & 74 & 1.8 & 41.7 \\
\hline 8 & Universidad Central de Venezuela & Venezuela & 89 & $(1.5)$ & 80 & 6.1 & 40.4 \\
\hline 9 & Universidade Federal de Ouro Preto & Brazil & 82 & (1.4) & 58 & 1.1 & 40.0 \\
\hline 10 & Universidade Estadual de Maringá & Brazil & 76 & $(1.3)$ & 35 & 1.6 & 39.9 \\
\hline 11 & Universidade Federal de São Paulo & Brazil & 72 & $(1.2)$ & 59 & 1.7 & 42.5 \\
\hline 12 & Universidad Peruana Cayetano Heredia & Peru & 65 & $(1.1)$ & 97 & 6.4 & 42.2 \\
\hline 13 & Universidad de Antioquia & Colombia & 61 & $(1.0)$ & 68 & 5.5 & 41.7 \\
\hline
\end{tabular}




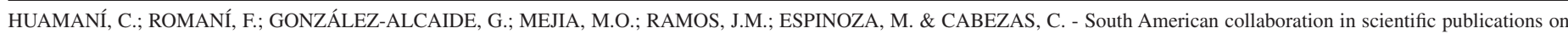
leishmaniasis: bibliometric analysis in SCOPUS (2000-2011). Rev. Inst. Med. Trop. Sao Paulo, 56(5): 381-90, 2014.

Table 3

Bibliometric indicators of the institutions with the largest number of signatures in original articles on leishmaniasis produced by South American countries in SCOPUS, 2000-2011 (cont.)

\begin{tabular}{|c|c|c|c|c|c|c|c|}
\hline Order & Institution & Country & Papers & $(\%)$ & Degree & $\begin{array}{c}\text { Interm. } \\
\text { x } 100\end{array}$ & $\begin{array}{c}\text { Proximity } \\
\text { x } 100\end{array}$ \\
\hline 14 & Universidade Federal do Piauí & Brazil & 55 & $(0.9)$ & 46 & 1.0 & 40.1 \\
\hline 15 & Universidade Estadual de Campinas & Brazil & 53 & $(0.9)$ & 33 & 1.1 & 40.1 \\
\hline 16 & Universidade de Brasília & Brazil & 52 & $(0.9)$ & 55 & 2.7 & 42.3 \\
\hline 17 & Centro Internacional de Entrenamiento e Investigaciones Médicas & Colombia & 51 & $(0.9)$ & 50 & 3.1 & 39.8 \\
\hline 18 & Universidad de Los Andes & Colombia & 44 & $(0.8)$ & 36 & 2.4 & 35.3 \\
\hline 19 & Universidade Federal do Maranhão & Brazil & 43 & $(0.7)$ & 45 & 1.0 & 39.8 \\
\hline 20 & Universidade Federal do Rio Grande do Norte & Brazil & 41 & $(0.7)$ & 50 & 1.3 & 40.0 \\
\hline 21 & Universidade Federal do Ceará, Fortaleza & Brazil & 40 & $(0.7)$ & 29 & 0.7 & 38.1 \\
\hline 22 & London School of Hygiene and Tropical Medicine & U.K. & 38 & $(0.7)$ & 93 & 4.3 & 43.9 \\
\hline 23 & Universidade Federal de Mato Grosso do Sul & Brazil & 38 & $(0.7)$ & 28 & 0.8 & 37.5 \\
\hline 24 & Universidade Federal Fluminense & Brazil & 37 & $(0.6)$ & 25 & 0.6 & 38.5 \\
\hline 25 & Universidade Federal de Pernambuco & Brazil & 35 & $(0.6)$ & 41 & 2.0 & 39.8 \\
\hline 26 & Instituto Venezolano de Investigaciones Científicas & Venezuela & 32 & $(0.6)$ & 32 & 2.3 & 38.7 \\
\hline 27 & Administración Nacional de Laboratorios e Institutos de Salud & Argentina & 30 & $(0.5)$ & 50 & 3.6 & 39.3 \\
\hline 28 & National Institutes of Health & USA & 29 & $(0.5)$ & 52 & 3.1 & 41.8 \\
\hline 29 & Universidad de Carabobo & Venezuela & 27 & $(0.5)$ & 39 & 1.5 & 39.3 \\
\hline 30 & Instituto Adolfo Lutz & Brazil & 26 & $(0.4)$ & 19 & 0.3 & 37.2 \\
\hline 31 & Kochi University, Kohasu & Japan & 26 & $(0.4)$ & 34 & 1.2 & 31.2 \\
\hline 32 & University of California & USA & 26 & $(0.4)$ & 39 & 1.2 & 41.1 \\
\hline 33 & University of Glasgow & U.K. & 25 & $(0.4)$ & 42 & 0.9 & 41.1 \\
\hline 34 & Institut de Recherche pour le Développement & France & 24 & $(0.4)$ & 44 & 2.6 & 39.1 \\
\hline 35 & Universidad Nacional de Colombia & Colombia & 24 & $(0.4)$ & 29 & 2.0 & 38.3 \\
\hline 36 & Universidade Federal de Juiz de Fora & Brazil & 24 & $(0.4)$ & 12 & 0.0 & 37.7 \\
\hline 37 & Universidade Federal do Espírito Santo & Brazil & 24 & $(0.4)$ & 23 & 0.7 & 38.3 \\
\hline 38 & Universidade Federal do Triângulo Mineiro & Brazil & 23 & $(0.4)$ & 23 & 0.7 & 38.1 \\
\hline 39 & Consejo Nacional de Investigaciones Científicas y Técnicas & Argentina & 22 & $(0.4)$ & 59 & 2.7 & 37.4 \\
\hline 40 & University of Cambridge, Cambridge & U.K. & 22 & $(0.4)$ & 42 & 1.1 & 41.7 \\
\hline 41 & Universidad Autónoma de Madrid & Spain & 21 & $(0.4)$ & 26 & 1.0 & 39.5 \\
\hline 42 & Universidade Federal do Paraná & Brazil & 21 & $(0.4)$ & 29 & 1.4 & 38.9 \\
\hline 43 & Universidade do Estado do Rio de Janeiro & Brazil & 21 & $(0.4)$ & 21 & 0.4 & 38.9 \\
\hline 44 & University of Washington & USA & 21 & $(0.4)$ & 69 & 2.0 & 42.5 \\
\hline 45 & Escola Bahiana de Medicina e Saúde Pública & Brazil & 20 & $(0.3)$ & 21 & 0.1 & 37.5 \\
\hline 46 & Universidad de Buenos Aires & Argentina & 20 & $(0.3)$ & 25 & 0.7 & 32.0 \\
\hline 47 & Universidade Federal do Pará & Brazil & 20 & $(0.3)$ & 24 & 0.2 & 38.6 \\
\hline 48 & University of Iowa & USA & 19 & $(0.3)$ & 34 & 0.4 & 39.5 \\
\hline 49 & University of Texas & USA & 19 & $(0.3)$ & 35 & 3.0 & 41.5 \\
\hline
\end{tabular}




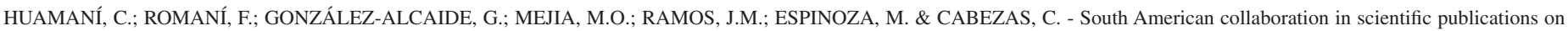
leishmaniasis: bibliometric analysis in SCOPUS (2000-2011). Rev. Inst. Med. Trop. Sao Paulo, 56(5): 381-90, 2014.

Table 4

Non-South American countries with the largest number of signatures in original articles on leishmaniasis produced by South American countries, 2000-2011

\begin{tabular}{lccl}
\hline Country & Frequency & $\%$ & Institutions with more production ${ }^{\mathbf{a}}$ \\
\hline USA & 415 & 7.1 & NIH (29), Univ. California (26), Univ. Washington (21) \\
UK & 206 & 3.5 & London School of Hygiene and Tropical Medicine (38), Univ. Glasgow (25), Univ. Cambridge (22) \\
France & 111 & 1.9 & Institut de Recherche pour le Développement (24), Univ. Toulouse (9), Univ. Paris-Sud (7) \\
Spain & 111 & 1.9 & Univ. Autónoma de Madrid (21), Instituto de Parasitología y Biomedicina Lopez-Neyra (14), Insti- \\
& 75 & 1.3 & Univ. Kochi (26), Univ. of the Ryukyus (17), Univ. Yamaguchi (11) \\
Japan & 68 & 1.2 & Univ. Wurzburg (14), Charité Univ. Med (4) \\
Germany & 52 & 0.9 & Institute of Tropical Medicine (16), Institut Prince Leopold (15), Univ. Antwerp (7) \\
Belgium & 50 & 0.9 & Univ. MacGill (9), Univ. Laval (7), Centre de Recherche en Infectiologie (5) \\
Canada & 46 & 0.8 & Word Health Organization (12), Univ. Geneva (11), Swiss Tropical and Public Health Institute (6) \\
Switzerland & 20 & 0.3 & Univ. degli Studi di Bari (6) \\
Italy & 15 & 0.3 & Royal Tropical Institute (7) \\
betherland & 14 & 0.2 & Centro de Investigación Científica de Yucatán (3) \\
Mexico & & &
\end{tabular}

a Only three institutions with the largest number of articles. ${ }^{\mathbf{b}}$ Other institutions have only one article.

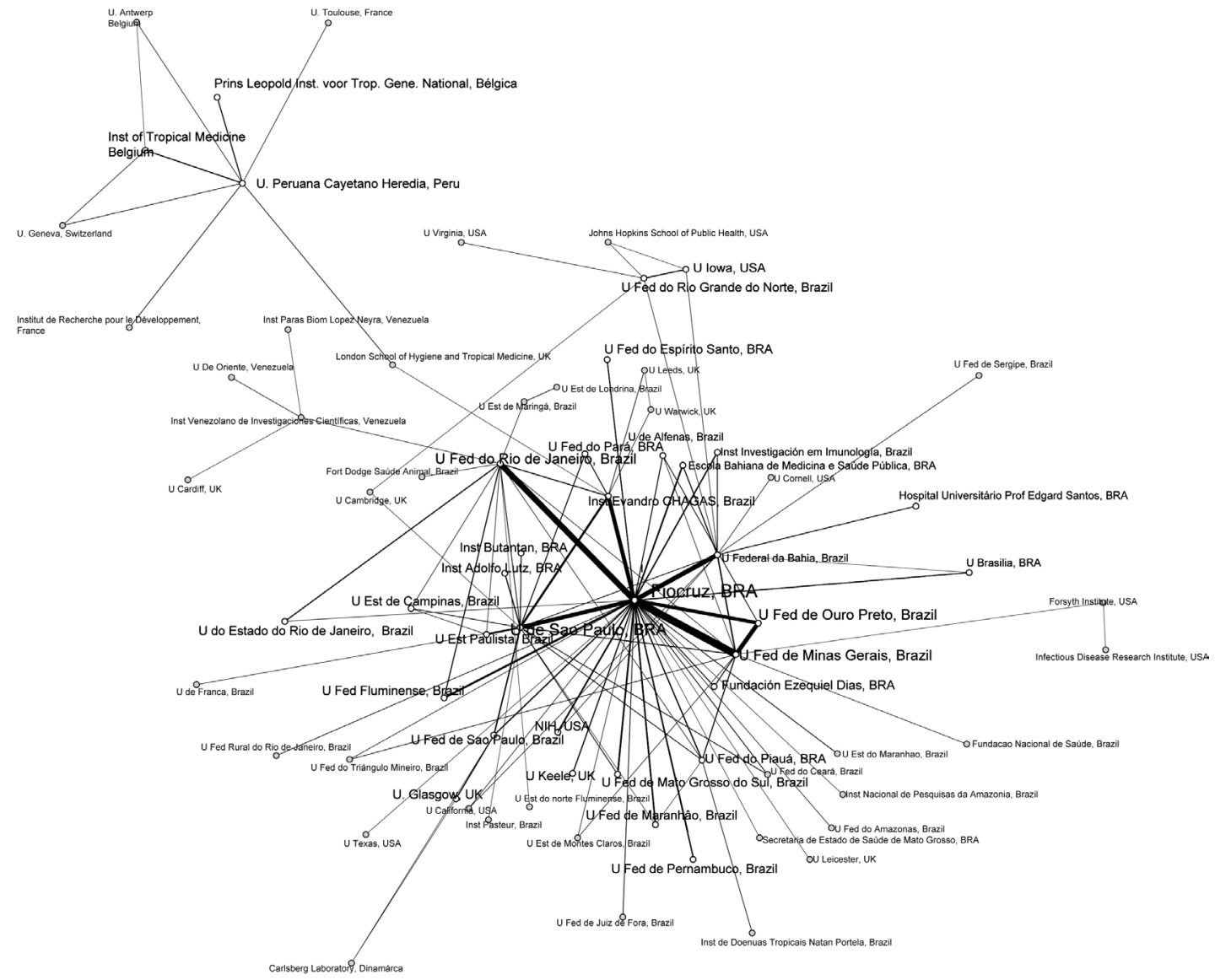

Fig. 2 - Primary South American collaborative network for the production of research articles on leishmaniasis. 
HUAMANÍ, C.; ROMANí, F.; GONZÁLEZ-ALCAIDE, G.; MEJIA, M.O.; RAMOS, J.M.; ESPINOZA, M. \& CABEZAS, C. - South American collaboration in scientific publications on leishmaniasis: bibliometric analysis in SCOPUS (2000-2011). Rev. Inst. Med. Trop. Sao Paulo, 56(5): 381-90, 2014.
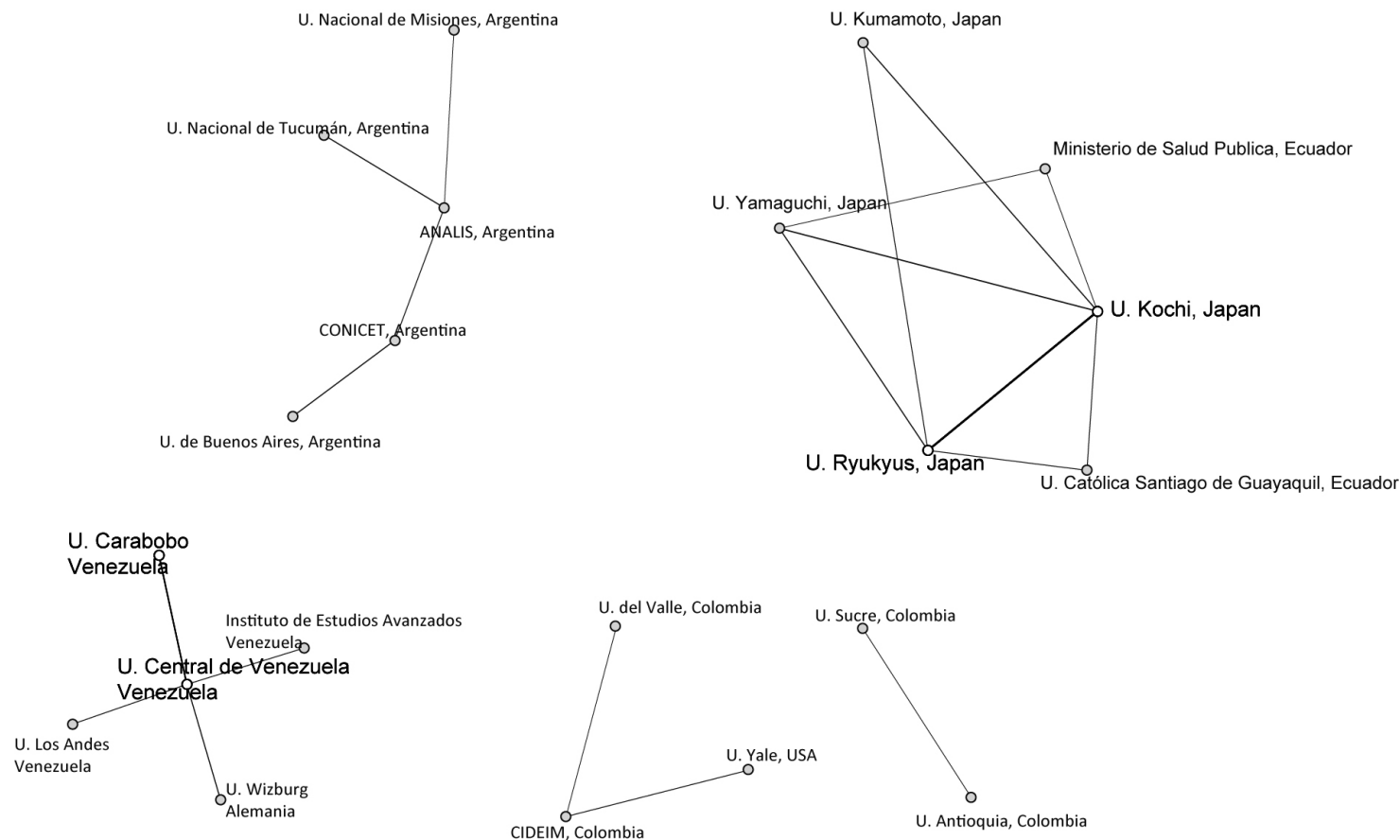

Fig. 3 - Smaller South American collaborative networks for the production of research articles on leishmaniasis.

The forgotten disease condition for leishmaniasis is exemplified in Peru, for example, by the very active collaborations that Cayetano Heredia University has with more than ten North American institutions in cancer research and with more than 20 institutions in clinical medicine research ${ }^{13}$, while the collaboration intensity with North American institutions is lower. Although leishmaniasis research is a specific area of development and can be carried out by fewer institutions, this does not mean that they are to be isolated from other foreign collaborators and institutions. On the contrary, as there are few national institutions researching it, collaborative work is needed (especially with foreign institutions), in order to increase their production.

Peruvian-Belgian collaboration, specifically that between the UPCH and the Institute of Tropical Medicine (Amberes, Belgium), has been described in its constitution, importance, and products ${ }^{9}$, by which the network described in our study reflects the results of such collaboration, which mainly comprises exchanges of researchers following training grants $^{10}$. Although studies showing the products of the collaboration between South American institutions with other countries have not been found yet, the Peruvian example (Peruvian-Belgian collaboration) may explain the results of the specific cooperation between Ecuador and Japan.

Brazil leads in the South American context, participating in more than $50 \%$ of the South American scientific production ${ }^{12}$, and is the country with most cases in the region. Its investment in development, science and technology, along with its research policies, has allowed it to address its own health problems and require less collaboration to maintain and increase its scientific production. In the area of neglected diseases, it leads South American research ${ }^{7}$ in Chagas disease following collaboration patterns similar to those described in our study. There are three factors that make Brazil the country with the highest production on leishmaniasis and, perhaps, also with other neglected diseases: i) the high number of new cases of cutaneous and visceral leishmaniasis ${ }^{2}$; ii) increased public spending in research \& development (the most in South America ${ }^{18}$; and iii) an active network of interinstitutional collaboration, something which increases research productivity ${ }^{3}$.

Globally, India leads scientific production on leishmaniasis. Following it are Brazil, Spain, the USA, and France ${ }^{1,16}$, however, the clinical form studied most is the visceral variety, which may explain why the remaining South American countries, which have a lower incidence of these clinical forms ${ }^{2}$, have less European or North American collaboration. The collaboration between these countries is focused in priority topics for European countries and the USA, and not in complete response to the research agendas of the South American countries. Theses agendas in several cases include neglected infectious diseases but those not prioritize leishmaniasis as a specific cause of disease burden. In this context, participation by UNASUR could play an integrating role in the promotion of research efforts within South America. The RINSUNASUR 2011-2015 five-year plan establishes the coordination of projects through the creation of thematic networks composed of staff members from UNASUR member countries with recognized expertise in the field of study on both national institutes of health, as well as university levels in these countries. One of the main proposed thematic networks is research on neglected infectious diseases. This initiative could focus research efforts on leishmaniasis, which, like dengue fever, is widespread throughout the region. It would also strengthen the leishmaniasis collaborative network on a regional level. The results of this study could serve as a baseline diagnosis to be used for comparison purposes, once the specified measures envisaged in the five-year plan materialize.

As for the distribution of the published articles, our sample appeared in almost 400 different journals. However, $32.3 \%$ of them are concentrated in only eight journals. Another research has reported 


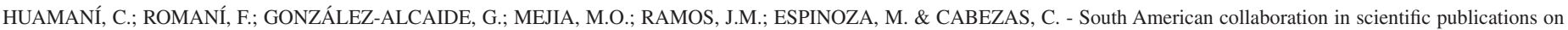
leishmaniasis: bibliometric analysis in SCOPUS (2000-2011). Rev. Inst. Med. Trop. Sao Paulo, 56(5): 381-90, 2014

the top eight journals accounting for $21 \%$ and $24 \%$ of the articles on leishmaniasis ${ }^{16}$. Seventy percent of the articles are distributed throughout 390 different journals. This nucleus of eight journals is comprised by two that are Brazilian (and are those that published the most) while the remaining six are not South American. Both Brazilian journals are institutional - Memórias do Instituto Oswaldo Cruz and the Revista da Sociedade Brasileira de Medicina Tropical belong to a public research institute and a medical society, respectively. They publish research on tropical diseases, preventive medicine, public health, and infectious diseases. Furthermore, both journals are free, which improves their visibility within the South American scientific community. If these results are compared with another study that explores worldwide production over a similar period of time (2000-2009), we can find some differences that can be explained by the geographic limits in our study. In that study, the journals with the highest publication of articles on leishmaniasis were Molecular and Biochemical Parasitology, Infection and Immunity, Experimental Parasitology, The American Journal of Tropical Medicine and Hygiene, and Parasitology Research. Although it is true that these journals are found among those with the most publications in our analysis, the order according to contribution is clearly different.

This study has some limitations. Our sample does not represent all the South American collaboration or actions taken to address the problems associated with leishmaniasis, as this may be reflected differently from a scientific publication (patents, clinical guidelines, among others) ${ }^{11}$. For example, the scientific production described does not represent the region's entire production, only research appearing in journals with international visibility. Therefore, it is possible that articles have been published about leishmaniasis in local journals that are not indexed by SCOPUS or MEDLINE. However, we felt that not including them would not affect our analysis of collaborative networks given that the production in local journals is less and because that research is conducted with less international collaboration. The IF was obtained from 2011 by JCR. This IF does not represent the whole period, but it is necessary to understand the current importance of the journals. Finally, it is possible that networks under construction are not evident in our network, since they still have to publish enough articles together. These will be revealed in subsequent studies, with our study serving as a baseline.

In conclusion, South American scientific production on leishmaniasis published in journals indexed in SCOPUS is focused on Brazilian activity. This activity integrates several institutions that collaborate primarily with FIOCRUZ and integrate Venezuelan and Peruvian institutions, but with little foreign participation, especially from South American countries. Networks producing less are those integrated by Ecuadorian-Japanese collaboration, or Venezuelan, Colombian or Argentinean institutions. It is possible that the South American collaborative networks will integrate the research factors from several countries as part of RINS-UNASUR soon, so we recommend that institutions interested in conducting or increasing their scientific production on leishmaniasis promote collaboration with the institutions nearest the center of these networks, i.e., those that demonstrate the highest values in collaboration and intermediation. All this considering that leishmaniasis is more than a neglected disease, it is a disease of forgotten or excluded populations, and finding solutions for its treatment (new and more effective drugs), prevention and control will only be possible by the attention paid and initiative shown by affected countries, providing the necessary funding and favoring collaborative work on a common problem.

\section{SPONSORSHIPS}

Self-funded.

\section{RESUMEN}

\section{Colaboración Sudamericana en publicaciones científicas sobre leishmaniasis: análisis bibliométrico en SCOPUS (2000-2011)}

Objetivos: Evaluar la producción y la red de colaboración de investigación sobre leishmaniasis en Sudamérica. Métodos: Se realizó un estudio bibliométrico usando la base de datos SCOPUS. La unidad de análisis fueron los artículos originales de investigación publicados desde el año 2000 hasta 2011, realizados sobre leishmaniasis y que incluyeron al menos un autor sudamericano. Se obtuvieron para cada artículo: nombre de la revista, idioma, año de publicación, número de autores, instituciones, países y otras variables. Resultados: 3174 artículos fueron publicados, 2.272 de ellos eran artículos originales. Se identificaron 1.160 firmas institucionales diferentes, 58 países y 398 revistas científicas. Brasil fue el país con más artículos $(60,7 \%)$ y la Fundación Oswaldo Cruz (FIOCRUZ) tuvo 18\% de la producción brasileña, convirtiéndose en el núcleo Sudamericano de la mayor red científica de Leishmaniasis. Conclusiones: La producción científica de Sudamérica sobre Leishmaniasis publicada en revistas indexadas en SCOPUS se centra en la actividad de la investigación brasileña. Es necesario fortalecer las redes de colaboración, el primer paso para ello es la identificación de las instituciones con mayor producción con el fin de llevar a cabo la investigación en colaboración de acuerdo con las prioridades de cada país.

\section{ACKNOWLEDGMENTS}

I wish to thank Dr Kim Hoffman for her recommendations to the final version.

\section{REFERENCES}

1. Al-Mutawakel K, Scutaru C, Shami A, Sakr M, Groneberg D, Quarcoo D. Scientometric analysis of the world-wide research efforts concerning leishmaniasis. Parasit Vectors 2010;3:14.

2. Alvar J, Vélez ID, Bern C, Herrero M, Desjeux P, Cano J, et al. Leishmaniasis worldwide and global estimates of its incidence. PLoS One. 2012;7:e35671.

3. Bales ME, Johnson SB, Keeling JW, Carley KM, Kunkel F, Merrill JA. Evolution of coauthorship in public health services and systems research. Am J Prev Med. 2011;41:112-7.

4. Caballero P, Yagui M, Espinoza M, Castilla T, Granados A, Velasquez A, et al. Prioridades regionales y nacionales de investigación en salud, Perú 2010-2014: un processo con enfoque participativo y descentralista. Rev Peru Med Exp Salud Publica. 2010;27:398411.

5. Chinchilla-Rodriguez Z, Benavent-Perez M, Moya-Anegon F, Miguel S. International collaboration in medical research in Latin America and the Caribbean (2003-2007). J Am Soc Inf Sci Technol. 2012;63:2223-38.

6. Desjeux P. Leishmaniasis: current situation and new perspectives. Comp Immunol Microbiol Infect Dis. 2004;27:305-18.

7. Gonzalez-Alcaide G, Park J, Huamani C, Gascón J, Ramos JM. Scientific authorships and collaboration network analysis on Chagas disease: papers indexed in PubMed (1940-2009). Rev Inst Med Trop Sao Paulo. 2012;54:219-28. 
HUAMANÍ, C.; ROMANí, F.; GONZÁLEZ-ALCAIDE, G.; MEJIA, M.O.; RAMOS, J.M.; ESPINOZA, M. \& CABEZAS, C. - South American collaboration in scientific publications on leishmaniasis: bibliometric analysis in SCOPUS (2000-2011). Rev. Inst. Med. Trop. Sao Paulo, 56(5): 381-90, 2014.

8. Goto H, Lindoso JA. Current diagnosis and treatment of cutaneous and mucocutaneous leishmaniasis. Expert Rev Anti Infect Ther. 2010; 8:419-33.

9. Gotuzzo E, Gonzalez E, Verdonck K. Formación de investigadores en el contexto de proyectos colaborativos: experiencias en el Instituto de Medicina Tropical "Alexander von Humbolt", Universidad Peruana Cayetano Heredia. Rev Peru Med Exp Salud Publica. 2010;27:419-27.

10. Guerra H. La beca de retorno de la Universidad Peruana Cayetano Heredia. Rev Peru Med Exp Salud Publica. 2010;27:428-31.

11. Holveck JC, Ehrenberg JP, Ault SK, Rojas R, Vasquez J, Cerqueira MT, et al. Prevention, control, and elimination of neglected diseases in the Americas: pathways to integrated, inter-programmatic, inter-sectoral action for health and development. BMC Public Health. 2007;7:6.

12. Huamani C, Gonzalez AG, Curioso WH, Pacheco-Romero J. Redes de colaboración y producción científica sudamericana en medicina clínica, ISI Current Contents 20002009. Rev Med Chil. 2012;140:466-75.

13. Huamani C, Mayta-Tristan P. Producción científica peruana en medicina y redes de colaboración, análisis del Science Citation Index 2000-2009. Rev Peru Med Exp Salud Publica. 2010;27:315-25.
14. Kamada T, Kawai S. An algorithm for drawing general undirected graphs. Inf Process Lett. 1989;31:7.

15. Pacheco Santos LM, Moura EC, Barradas Barata R de C, Serruya SJ, da Motta ML, Silva Elias FT, et al. Fulfillment of the Brazilian agenda of priorities in health research. Health Res Policy Syst. 2011;9:35.

16. Ramos JM, Gonzalez-Alcaide G, Bolanos-Pizarro M. Bibliometric analysis of leishmaniasis research in Medline (1945-2010). Parasit Vectors. 2013;6:55.

17. Reithinger R, Dujardin J, Louzir H, Pirmez C, Alexander B, Brooker S. Cutaneous leishmaniasis. Lancet Infect Dis. 2007;7:581-96.

18. UNESCO. The Current status of science around the World. Paris: UNESCO Science Report; 2010.

19. WHO. Neglected tropical diseases. Geneva: WHO; 2013. [cited 2013 Mar 19]. Available from: http://www.who.int/neglected_diseases/en/

Received: 3 October 2013

Accepted: 25 February 2014 